(continued from previous page)

The Finance Committee will continue to monitor the activities described above throughout the remainder of this year and beyond. And at the same time, it will pursue its responsibility to identify new sources of financial support for the Societ y's technical programming and to facilitate communication between government funding agencies and symposia organizers toward more rewarding interaction and expansion of the Society's educational programs.

The eagerness and dedication with which MRS members devote their time to tackling new ways for the Society to respond to the needs of the scientific community has been instilled in the Society from its inception. The Finance Committee supports these endeavors by contributing its expertise to ensure that new opportunities are addressed in a timely and responsible manner to facilitate the long, productive life of this vital organization.

*Don Harrison is chairperson of the Finance Committee

\title{
Applicants Sought for MRS Graduate Student Awards
}

\author{
Students to be Recognized at 1985 Fall Meeting
}

Applications are now being accepted for awards to be given at the 1985 Fall Meeting to graduate students conducting research in an area of materials science. Fifteen awards, to consist of a $\$ 250$ cash grant, registration fee for the Meeting, and a certificate of achievement, will be bestowed during the Awards Ceremony during the 1985 MRS Fall Meeting in Boston. The deadline for the receipt of applications is September 1, 1985.

The awards are given in recognition of a student's contribution to outstanding research in an area of interest to one or more of the topical symposia included in the Fall Meeting. The dominant criteria used in the selection process are scientific excellence and the demonstrated evidence of the student's contribution to the work. The paper need not be presented during the Fall Meeting to qualify, but participation in the Meeting will be considered in the selection process since one of the primary goals of the Awards Program is to encourage students to participate in the Meeting and to present their research accomplishments to the scientific community.

To obtain a Graduate Student Award application, contact MRS Headquarters, 9800 McKnight Road, Suite 327, Pittsburgh, PA 15237; telephone (412) 367-3003.

\section{Institute for Materials Science Established at University of Antwerp}

\author{
J. T. Devreese \\ Universitaire Instelling Antwerpen
}

On February 14, 1985, the University of Antwerp announced the formation of the Institute for Materials Science (IMS). This Institute is an association of 14 laboratories and research institutes located partly on its campus of Universitaire Instelling Antwerpen (UIA) and partly at the Rijksuniversitair Centrum Antwerpen (RUCA).

A considerable variety of physical and chemical techniques (both experimental and theoretical) are indispensable for the investigation of existing materials and for the development of new materials. Among the techniques used at IMS are:

- diffraction of electrons, neutrons and $x$ rays, electron- and ion microscopy;

- Mass spectrometry of gases, ions and compounds;

- infrared, nuclear magnetic resonance and laser-spectroscopy;

- Mössbauer spectrometry;

- optical absorption and light scattering;

- ab-initio computation of electronic structure of solids with the development of vectorized codes for supercomputers;

- sputtering and vapor deposition; and

- damping of mechanical vibrations.

The equipment available at the IMS includes instruments for the analysis of the structure and chemical properties of materials at the atomic and electronic level, with high spatial and temporal resolution and high sensitivity.

The IMS has three main objectives:
1. To conduct fundamental research into the physics and chemistry of materials. 2. To participate in national and international programs for research and technology for related materials science.

3. To provide facilities for research groups from industrial laboratories and, where possible, to provide services for joint ventures with industrial laboratories.

The IMS has over 150 staff members with the technical and theoretical expertise for the solution of materials problems.

Research at the IMS fits in with the current developments in materials research which have made possible the mastery of materials at the scale of atoms and atomic monolayers.

\section{FALL MEETING PROGRAM AND ABSTRACT BOOK}

This compact reference which contains an index to authors and chairs is an excellent compendium to the 14 proceedings and extended abstracts volumes to be published from the Meeting.

Send check for $\$ 5.00$ to:

Publications Department, Materials Research Society, 9800 McKnight Road, Suite 327, Pittsburgh, PA 15237, telephone: (412) 367-3003 